\title{
Diagnostic comparison of malaria infection in peripheral blood, placental blood and placental biopsies in Cameroonian parturient
} women

\author{
Judith K Anchang-Kimbi*1, Eric A Achidi ${ }^{2}$, Blaise Nkegoum³ \\ Eva Sverremark-Ekström ${ }^{4}$ and Marita Troye-Blomberg ${ }^{4}$
}

Address: ${ }^{1}$ Department of Plant and Animal Sciences, University of Buea, PO Box 63 Buea, Cameroon, ${ }^{2}$ Faculty of Health Sciences, University of Buea, Cameroon, ${ }^{3}$ Department of Anatomy and Pathology, University of Yaoundé Teaching Hospital, Cameroon and ${ }^{4}$ Department of Immunology, Wenner-Gren Institute, Stockholm University, Sweden

Email: Judith K Anchang-Kimbi* - kuoh2000@yahoo.fr; Eric A Achidi - achidi_e@yahoo.com; Blaise Nkegoum - nkegoum@yahoo.fr; Eva Sverremark-Ekström - eva.sverremark@imun.su.se; Marita Troye-Blomberg - marita@imun.su.se

* Corresponding author

Published: 8 June 2009

Malaria Journal 2009, 8:126 doi:10.1186/1475-2875-8-126
Received: 30 January 2009

Accepted: 8 June 2009

This article is available from: http://www.malariajournal.com/content/8/I/126

(C) 2009 Anchang-Kimbi et al; licensee BioMed Central Ltd.

This is an Open Access article distributed under the terms of the Creative Commons Attribution License (http://creativecommons.org/licenses/by/2.0), which permits unrestricted use, distribution, and reproduction in any medium, provided the original work is properly cited.

\begin{abstract}
Background: In sub-Saharan Africa, Plasmodium falciparum malaria in pregnancy presents an enormous diagnostic challenge. The epidemiological and clinical relevance of the different types of malaria diagnosis as well as risk factors associated with malaria infection at delivery were investigated.
\end{abstract}

Method: In a cross-sectional survey, 306 women reporting for delivery in the Mutenegene maternity clinic, Fako division, South West province, Cameroon were screened for P. falciparum in peripheral blood, placental blood and placental tissue sections by microscopy. Information relating to the use of intermittent preventive treatment in pregnancy with sulphadoxine/pyrimethamine, history of fever attack, infant birth weights and maternal anaemia were recorded.

Results: Among these women, $P$. falciparum infection was detected in $5.6 \%, 25.5 \%$ and $60.5 \%$ of the cases in peripheral blood, placental blood and placental histological sections respectively. Placental histology was more sensitive $(97.4 \%)$ than placental blood film $(41.5 \%)$ and peripheral blood $(8.0 \%)$ microscopy. In multivariate analysis, age $(\leq 20$ years old) $(\mathrm{OR}=4.6 \mathrm{I}, 95 \% \mathrm{Cl}=1.47$ $-14.70)$, history of fever attack $(O R=2.98,95 \% \mathrm{Cl}=1.58-5.73)$ were significant risk factors associated with microscopically detected parasitaemia. The use of $\geq 2 \mathrm{SP}$ doses (OR $=0.18,95 \%$ $\mathrm{Cl}=0.06-0.52$ ) was associated with a significant reduction in the prevalence of microscopic parasitaemia at delivery. Age $(>20$ years $)(O R=0.34,95 \% \mathrm{Cl}=0.15-0.75)$ was the only significant risk factor associated with parasitaemia diagnosed by histology only in univariate analysis. Microscopic parasitaemia $(O R=2.74,95 \% \mathrm{Cl}=1.33-5.62)$ was a significant risk factor for maternal anaemia at delivery, but neither infection detected by histology only, nor past infection were associated with increased risk of anaemia.

Conclusion: Placenta histological examination was the most sensitive indicator of malaria infection at delivery. Microscopically detected parasitaemia was associated with increased risk of maternal anaemia at delivery, but not low-grade parasitaemia detected by placental histology only. 


\section{Background}

Malaria due to Plasmodium falciparum infection during pregnancy is a serious public health problem in sub-Saharan Africa. One woman in four has evidence of placental infection at the time of delivery $[1,2]$. It is well known that infection with malaria during pregnancy leads to the selective adherence of infected erythrocytes (IEs) in the placenta [3-5]. Plasmodium falciparum erythrocyte membrane protein 1 (var2csa PfEMP1) is the principal chondroitin sulfate A (CSA) binding ligand mediating placental sequestration of IEs [6]. Consequently higher numbers of IEs containing mature trophozoite and schizont stage parasites may be found in the placenta [4], to higher densities than in the peripheral circulation. Sequestration of parasites in the intervillous spaces (IVS), contributes to maternal morbidity, low birth weight, and preterm delivery $[1,7]$. Moreover, malaria in pregnancy is an important cause of severe anaemia in pregnant African women [8].

Placental malaria (PM) is one of the major features of malaria during pregnancy and has been widely used as a standard indicator to characterize malaria infection in epidemiologic investigations [9]. A number of factors influence the prevalence of malaria in pregnant women, including maternal age, gravidity, use of prophylaxis, nutrition, host genetics, level of anti-parasite immunity, as well as parasite genetics and transmission rates [10]. The prevalence and risk factors of placental malaria in sub-Saharan Africa have been assessed based on different definitions of placental malaria using diverse techniques of sample collection and analysis [9]. Some studies based their definition on the presence of malaria parasite and/or pigments in blood smears from placental blood [10-13]. Others based their definition on histological findings [7,14-16], histidine-rich-protein-2 (HRP2) capture test $[17,18]$ and polymerase chain reaction (PCR) [18-20].

Placental histology is considered the "gold standard" of malaria diagnosis in pregnancy for epidemiological or biological study purposes, because it can show signs of active (presence of IEs only in the IVS), active chronic (presence of IEs and pigment in monocytes) or past (malarial pigment in fibrin) infections [21,22]. However, due to limited technical expertise, such testing is rarely available in endemic areas. Most studies in sub-Saharan Africa have relied on the results of the placental blood smear [9], the sensitivity of which is low compared with placental histopathology [16].

This study: i) determined and compared malaria infection at delivery in maternal peripheral blood, placental blood and placental histological sections; ii) assessed the epidemiological and clinical significance of $P$. falciparum infections detected by blood smear microscopy, histology only and past infection, as well as risk factors associated with malaria infection at delivery.

\section{Methods}

\section{Study area and population}

The study was conducted in the Mutengene health area from March to October 2007. Mutengene is a semi-urban, road-junction town, located in the Mt Cameroon region, Fako Division of the South West Province of Cameroon. The Mutengene medical centre is the only governmentowned institution that offers antenatal care, preventive and curative services at affordable cost in the health area. This town is located at about $220 \mathrm{~m}$ above sea level and has a heterogeneous population of approximately 40,000 inhabitants who originate mainly from neighbouring provinces in search of its fertile farmland and business opportunities [11,23].

The Mt Cameroon region has an equatorial climate made up of a long rainy season that starts in March and ends in October with maximum rainfall in August and September. The dry season starts in late October and ends in February. The mean value of the minimum temperature varies between $20.0^{\circ} \mathrm{C}$ in December and $18.0^{\circ} \mathrm{C}$ in August and the mean value of the maximum temperature ranges between $35.0^{\circ} \mathrm{C}$ in February and $30.0^{\circ} \mathrm{C}$ in March [23]. Mutengene is characterized by mean temperatures of $25.1^{\circ} \mathrm{C}$ and mean relative humidity of $83.1 \%$ (Cameroon Development Corporation (CDC) weather records, 2004).

The Mt Cameroon region is hyperendemic for malaria, with $P$. falciparum being the predominant malaria parasite species [24]. A previous study on malaria in pregnancy in Mutengene from 1998-2001 recorded malaria parasite rates of $32.7 \%, 33.7 \%$ and $7.8 \%$ in maternal, placental and cord blood respectively [13]. In addition, this study showed that anaemia is a major health problem in this area and malaria contributes about $50 \%$ of the anaemic cases [11]. Intermittent preventive treatment in pregnancy (IPTp), using regular treatment doses of the antimalarial sulphadoxine/pyrimethamine (SP) was introduced as a national policy in Cameroon in 2003 and implementation is still in progress [25]. The study received ethical clearance from the Delegation of Public health, Buea, South West Province.

\section{Sample collection and processing}

Pregnant women reporting for delivery at the Mutengene maternity health centre and who consented to participate in the study were enrolled. Expectant mothers with evidence of chronic illness and complicated pregnancy (hypertension, preeclampsia, diabetes) were not eligible and cases of multiple pregnancies were excluded. All maternal and infant characteristics (age, gravidity, gesta- 
tional age, birth weights, number of antenatal visits, SP dosage, and history of fever attack during pregnancy) were documented using a standard questionnaire. IPT/SP during pregnancy is administered during antenatal visits under the supervision of a midwife who records and signs in patients' antenatal case report book. SP dosage and compliance and history of fever attack were confirmed from the patient's medical record book and by personal interview. Human immunodeficiency virus (HIV) infection status was known for mothers recruited. Women in this setting are offered routine confidential HIV testing at first antenatal clinic (ANC) visit, but testing was done at delivery for women who had no antenatal follow-up or had enrolled in maternity clinics out of the study area with no ANC cards. We did not obtain informed consent to publish data on HIV status of the participants.

Maternal peripheral venous blood ( $2 \mathrm{ml}$ ) was collected by venopuncture within 24 hours of parturition and used to prepare thick blood films. Immediately following delivery, the placenta was obtained and a small piece of placental tissue $\left(0.5 \mathrm{~cm}^{3}\right)$ excised from the centre of the placenta and used to prepare impression smears. A larger biopsy specimen of placental tissue ( 2 by 2 by $1 \mathrm{~cm}$ ) was fixed in $10 \%$ neutral buffered formalin for histopathological studies.

\section{Parasitological examination}

Placental impression smears were fixed in methanol and together with thick films stained for 20 mins with 5\% Giemsa (Sigma). Fixed placental biopsies were transferred to the Anatomy and Pathology (ANAPATH) Laboratory, University of Yaoundé I Teaching Hospital (CHU), Yaoundé, Cameroon, where they were processed, embedded in paraffin wax and sectioned onto slides by standard techniques. Sections were later stained with haematoxylin-eosin stain for detection of active and past infections. Microscopic examination of blood smears was done under oil immersion for parasite detection and 200 high power fields were examined before the smear was considered negative. Parasites were counted against 200 leucocytes assuming an average leucocyte count of 8,000 per microlitre of blood [26]. To determine the percentage of malaria parasitaemia from placental impression smears, malaria parasite-infected red cells were counted against 1,000 erythrocytes.

Placental histological sections were first examined by the one of the investigators (JKA) and later confirmed by a more experienced histopathologist (BN) without knowledge of the blood film microscopy results. One thousand intervillous cells (IVS) were counted to determine the level of parasitaemia in placenta tissue sections. Past infection was defined as the presence of malaria pigment in fibrin or monocyte/macrophage without malaria para- sites [14]. Histology was re-examined in all cases in which histology and blood film results were in disagreement. Sections were observed under polarised light to assess the presence of malaria pigment [27].

\section{Haematological analysis}

Heparinized, microhaematocrit tubes were filled with a sample of peripheral blood and centrifuged using a microhaematocrit centrifuge. The haematocrit (packed cell volume (PCV) was read using haematocrit reader (Hawksley). Haemoglobin concentration was calculated from PCV values as described by Topley [28]. Anaemia was defined as $\mathrm{Hb}<11.0 \mathrm{~g} / \mathrm{dl}$ [29].

\section{Statistical analyses}

All data were entered and analysed using SPSS version 11.5. Malaria infection at delivery was classified as microscopic parasitaemia detected by blood smear microscopy, parasitaemia by histology only, past infection and no malaria. Associations of the different types of malaria diagnosis with age group, parity, use and doses of IPTp-SP and history of fever attack were evaluated using Pearson Chi-Square $\left(\chi^{2}\right)$ test, odds ratio (OR) test in univariate analyses and logistic regression in multivariate analyses. Differences in group means were assessed using ANOVA, Mann-Whiney U test or Kruskall Wallis test. Age and parity was categorized as follows: age $(\leq 20,21-25,>25)$ years and parity (primiparae, secundiparae and multiparae ( $\geq 3$ pregnancies), use of SP (no SP, 1 dose and $\geq 2$ doses), fever history (fever attack $=$ Yes, No fever attack $=$ No). Statistical significance was set at $\mathrm{p} \leq 0.05$.

\section{Results \\ Description of study participants}

A total of 306 women delivering at the Mutengene matenity ward were recruited. The mean age of the mothers was $23.8 \pm 5.2$ (range; $14-40$ ) years, where primiparae (19.5 \pm $2.4)$ were significantly younger $(\mathrm{p}<0.001)$ compared with secundiparae $(22.6 \pm 3.0)$ and multiparae $(28.2 \pm$ 4.6). Among the women, $90.1 \%$ (272/302) reported taking IPTp-SP during pregnancy. For women with number of doses recorded, $47.8 \%(129 / 270)$ had taken one dose, $52.2 \%$ (141/270) took two or more doses and 9.9\% (30/ 302) did not take SP during the entire pregnancy period. Peripheral blood was collected from 287. Reported history of fever was $43.6 \%(125 / 287)$. One hundred and seventy-six $(63.3 \% ; 278)$ women were anaemic at delivery and the prevalence of low birth weight was 5.6\% (17) 306). The prevalence of HIV infection among women recruited was 5.6\%; (17/306).

\section{Detection and prevalence of malaria infection}

Sixteen women $(5.6 \% ; 16 / 287)$ had malaria parasite infection diagnosed by peripheral blood microscopy. Seventy-eight $(25.5 \% ; 78 / 306)$ had placental infection diag- 
nosed by placental blood smear examination. Of the $25 \%$ diagnosed by placental blood smear, $19.6 \%(60 / 306)$ were with active infection while $5.9 \%(18 / 306)$ had past infection. Placental histological examination detected 185 $(60.5 \%, 185 / 306)$ placental malaria positive women. Of these, $33.7 \%$ (103) had active placental infections while $26.8 \%$ (82) had past infection. Overall, 39.2\% (120/306) had active $P$. falciparum infection, defined as the presence of malaria parasites as detected in thick peripheral blood, placental impression blood films or placental tissue sections. Of the active infections, $44.2 \%$ (53) were detected by histology only and $55.8 \%$ (67) by blood smear microscopy and histology. Of the $82(26.8 \%)$ women with past infection on histology, 12 were positive for malaria parasites on blood smear microscopy (3 positive on peripheral blood and 9 on placental blood) thus the overall prevalence of past infection was $22.9 \%$ (70). The cumulative prevalence of malaria infection at delivery (total number of women positive for malaria either by histology or peripheral and placental blood smear examination was 62.1\% (190/306).

Placental histology detected all but three of the placental infections detected by placental blood smear examination, as well as all but two of the malaria infection detected by peripheral blood smear; giving a sensitivity of
97.4\%. One hundred and ten women with histological evidence of placental infection were missed on placental blood smear, which had a sensitivity of $41.5 \%$. One hundred and sixty-one women positive by placental histology were missed on peripheral blood examination, which had a sensitivity of $8 \%$ (Figure 1). The overall prevalence of placental malaria at delivery was $61.4 \%(188 / 306)$. There was a significant positive correlation between parasitaemia levels determined by placental blood smear and tissue sections $(\mathrm{r}=0.757 ; \mathrm{p}<0.001)$. Among the women in whom malaria parasite was detected by histology only, the median (range) placental parasite density was $0.38 \%$ $(0.10$ to $3.2 \%)$ lower $(p<0.001)$ compared to that for women with positive placental blood smears $(0.83 \%$; range, 0.11 to $57.27 \%$ ). Generally, placental parasites were usually scarce: $66.1 \%(76 / 115)$ of actively infected placentas had parasitaemia less than $1 \%$ whereas only $12.2 \%(14 / 115)$ showed $10 \%$ or more parasitized erythrocytes.

\section{Factors influencing the prevalence of malaria infection at delivery}

Microscopically detected parasitaemia was the only clinically relevant malaria infection at delivery and factors influencing its presence were analysed (Table 1). In multivariate analysis, younger age ( $\leq 20$ years) and reported

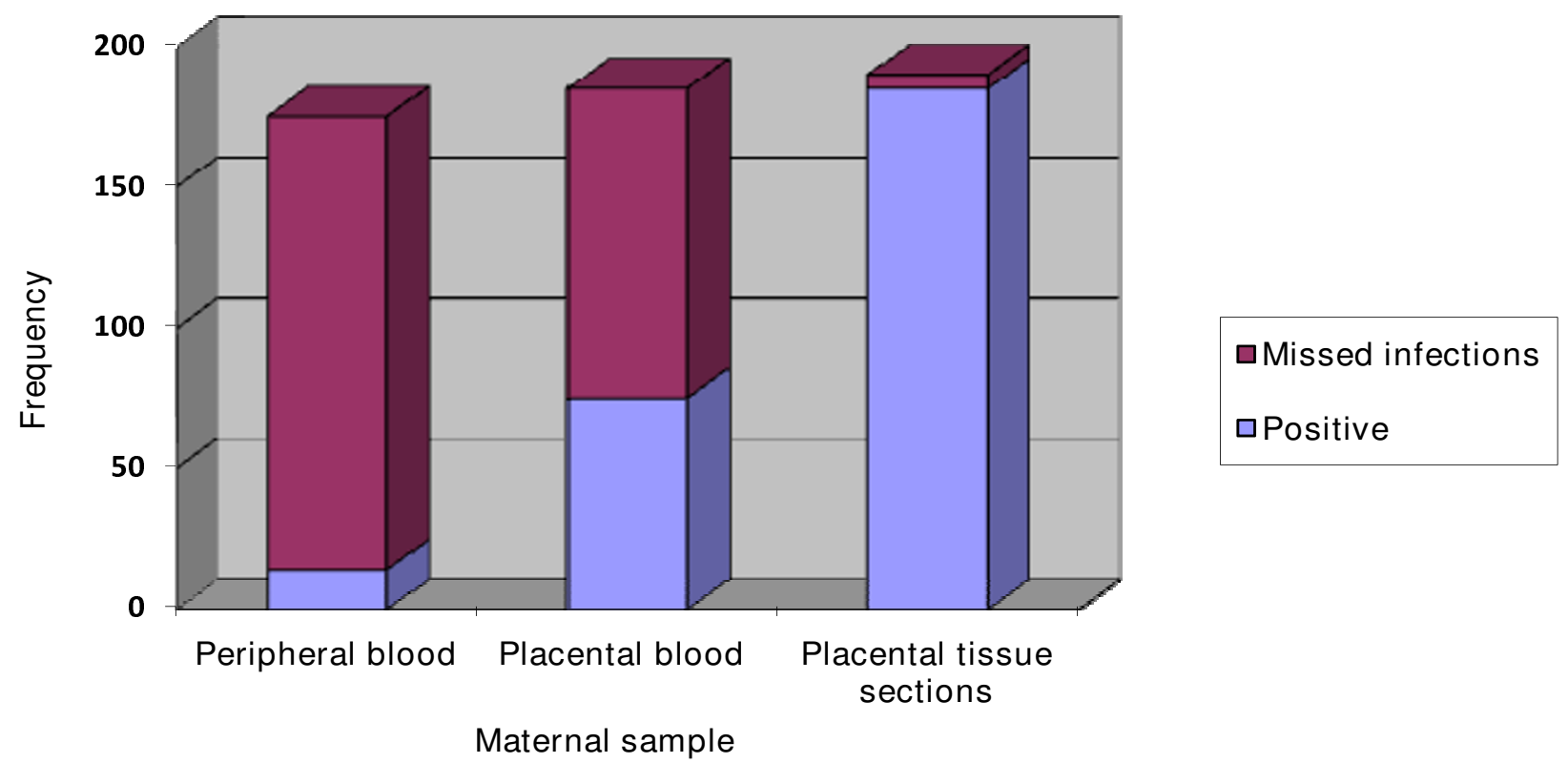

\section{Figure I}

Frequency distribution of malaria infection in peripheral blood, placental blood and placental tissue sections. Malaria infection was defined as presence of malaria parasites, malaria pigment (haemozoin) in monocytes and/or fibrin detected by microscopy in maternal peripheral blood, placental blood and placental tissue sections from parturient women. 
Table I: Risk factors of microscopic parasitaemia

\begin{tabular}{|c|c|c|c|c|c|}
\hline \multirow[t]{2}{*}{ Factors } & \multirow[t]{2}{*}{$\%$ positive } & \multicolumn{2}{|c|}{ Univariate analysis } & \multicolumn{2}{|c|}{ Multivariate analysis } \\
\hline & & OR $(95 \% \mathrm{Cl}) *$ & $P$ & OR $(95 \% \mathrm{Cl}) \dagger$ & $P$ \\
\hline \multicolumn{6}{|l|}{ Age (years)(n) } \\
\hline$\leq 20(94)$ & $31.9(30)$ & $2.69(1.34-5.4 I)$ & 0.005 & $4.6 \mid(1.47-\mid 4.70)$ & 0.01 \\
\hline $21-25(108)$ & $18.5(20)$ & $1.30(0.63-2.71)$ & 0.478 & $2.03(0.80-5.20)$ & 0.137 \\
\hline$>25(101)$ & $14.9(15)$ & Reference & & & \\
\hline \multicolumn{6}{|l|}{ Parity (n) } \\
\hline I (95) & $29.5(28)$ & $1.78(0.95-3.35)$ & 0.072 & $0.61(0.22-1.69)$ & 0.337 \\
\hline II (90) & $17.8(16)$ & $0.92(0.46-1.87)$ & 0.820 & $0.40(0.15-1.06)$ & 0.064 \\
\hline$\geq \mathrm{III}(12 \mathrm{I})$ & $19.0(23)$ & Reference & & & \\
\hline \multicolumn{6}{|l|}{ SP dosage (n) } \\
\hline$\geq 2(141)$ & $\mid 4.9(2 \mid)$ & $0.26(0.11-0.62)$ & 0.002 & $0.18(0.06-0.52)$ & 0.002 \\
\hline I (I29) & $24.0(31)$ & $0.47(0.21-1.09)$ & 0.076 & $0.31(0.11-0.88)$ & 0.028 \\
\hline No SP (30) & $40.0(12)$ & Reference & & & \\
\hline \multicolumn{6}{|l|}{ Fever history (n) } \\
\hline Yes (125) & $28.8(36)$ & $2.45(1.36-4.40)$ & 0.002 & $2.98(1.58-5.73)$ & 0.001 \\
\hline No (162) & $14.2(23)$ & Reference & & & \\
\hline
\end{tabular}

$\mathrm{OR}=$ odds ratio; $\mathrm{Cl}=$ confidence interval

* Estimated by Pearson-Chi-Square

† Estimated by multivariate logistic regression including all risk factors in the table

fever history were independent risk factors associated with microscopic parasitaemia while the use of $\geq 1$ SP doses was associated with reduction in the prevalence of infection. Parity was not associated with microscopic infections neither in univariate nor multivariate analyses. Nevertheless, past infections were common $\left(\chi^{2}=6.328\right.$; $\mathrm{p}$ $=0.042)$ in primiparous $(31.6 \%)$ compared to secundiparous $(21.1 \%)$ and multiparous $(17.4 \%)$ women. The presence of infections detected by histology only (low-grade parasitaemia) was significantly associated with age $(>20$ years $)(\mathrm{OR}=0.34,95 \% \mathrm{CI}=0.15-0.75)$ where infections detected by histology only were more common $\left(\chi^{2}=\right.$ $7.616 ; \mathrm{p}=0.006)$ in women $>20$ years old $(20.8 \%)$ than in those $\leq 20$ years $(8.5 \%)$. Parity, SP dosage, or fever history were not associated with the prevalence of low-grade infection.
The effect of malaria infection status at delivery on infant birth weight and maternal anaemia

The mean birth weights of babies did not differ with malaria infection status, while mean haemoglobin concentrations were significantly lower in women with microscopically detected infection compared to uninfected women (Table 2). Similarly, microscopic parasitaemia $(\mathrm{OR}=2.74,95 \% \mathrm{CI}=1.33-5.62)$ was a significant $(\mathrm{p}$ $=0.006 ; 49 / 62)$ risk factor for maternal anaemia at delivery, but low-grade parasitaemia $(\mathrm{OR}=0.61,95 \% \mathrm{CI}=$ $0.31-1.22 ; \mathrm{p}=0.162 ; 22 / 48)$ and past infections $(\mathrm{OR}=$ $1.73,95 \% \mathrm{CI}=0.89-3.39 ; \mathrm{p}=0.106 ; 43 / 61)$ did not significantly increase the risk of anaemia.

Table 2: Comparison of birth weight $(\mathrm{kg})$ and maternal haemoglobin levels $(\mathrm{g} / \mathrm{dl})$ according to presence or absence of malaria infection as detected by microscopy and histology

\begin{tabular}{lll}
\hline Infection classification $^{a}$ & Birth weight $(\mathrm{kg})( \pm \mathrm{SD})$ & $\mathrm{Hb}(\mathrm{g} / \mathrm{dl})( \pm \mathrm{SD})$ \\
\hline Malaria on microscopy & $3.18 \pm 0.54(67)^{b}$ & $9.59 \pm 1.87(62)^{* * * * c}$ \\
Malaria on histology only & $3.40 \pm 0.49(53)^{d}$ & $10.90 \pm 1.38(48)^{\mathrm{e}}$ \\
Past malaria & $3.22 \pm 0.52(70)^{f}$ & $10.33 \pm 1.29(61)^{g}$ \\
No malaria & $3.31 \pm 0.12(116)$ & $10.57 \pm 1.67(107)$ \\
\hline
\end{tabular}

**** Significant

a Malaria on microscopy: parasites identified by peripheral and placental blood

microscopy; malaria on histology only, parasites identified by histology only but not blood smear microscopy; past malaria infection, malaria pigment identified by histology with negative blood film microscopy; no malaria, no parasites by blood smear microscopy nor placental histology.

${ }^{b} \mathrm{P}=0.09 c \mathrm{P}<0.001, \mathrm{~d} \mathrm{P}=0.283$, e $\mathrm{P}=0.229, \mathrm{fP}=0.214, \mathrm{~s}_{\mathrm{p}}=0.346$ represent comparison with placentas with no $P$. falciparum infection. 


\section{Discussion}

This study determined the prevalence of malaria infection and parasite density in Cameroonian parturient women using maternal peripheral blood microscopy, placental blood microscopy and placental histology. The epidemiological and clinical relevance of the different types of malaria diagnosis as well as some risk factors associated with malaria infection were investigated.

Overall, pregnant women in this semi-urban area of Cameroon were frequently (62.1\%) exposed to $P$. falciparum infection during pregnancy. Using blood smear microscopy, $21.9 \%$ of the women were found to harbour malaria parasites at delivery similar to findings reported in Yaoundé $[17,19]$. Malaria parasitaemia rate increased to $39.2 \%$ when the results of placental histology were added. Furthermore, microscopy of peripheral blood missed more microscopic placental infections, with 49 out of 60 women having a negative peripheral blood film. The observed sensitivity of placental histology is in accord with previous reports $[15,16,30]$ and emphasis the gross underestimation of placental malaria infection by peripheral blood microscopy in pregnant women living in endemic areas. It is possible that peripheral parasitaemia may remain below the levels of microscopic detection while parasites may be harboured by the placenta and evade circulation. Nevertheless some studies have reported high sensitivities of peripheral blood immunochromatographic (ICT) strip test that detects $P$. falciparum histidine-rich protein 2 (HRP-2) [17,31] and PCR, that amplifies $P$. falciparum-specific DNA for detection of lowlevel parasitemia or circulating genetic material [32] compared to peripheral blood microscopy in detecting microscopically confirmed placental Plasmodium falciparum $[19,31]$. Malaria in pregnancy has significant adverse effects on the mother and foetus. Consequently, early and accurate diagnosis of malaria in pregnancy is absolutely imperative. Obtaining results quickly from the examination of blood samples from pregnant women with suspected malaria is now made possible by the use of rapid malaria diagnostic tests (RDTs), although their use in developing countries is limited by their high cost and availability [33].

There was a significant positive correlation between parasitaemia levels determined by placental blood smear and tissue sections $(\mathrm{r}=0.757 ; \mathrm{p}<0.001)$, the median placental parasitaemia levels being higher in placental blood smears $(0.83 \%)$ compared to that detected in placental tissue sections $(0.38 \%)$. Two concepts are suggested. Firstly, impression smears correlate quite well with histology. Secondly, infection detected only by histology is lower level and potentially less significant than infection found on impression smears.
It is well established that primigravidae are indisputably at greater risk of malaria infection during pregnancy in stable malaria regions [34]. In the present study, parity was associated only with past infections. Similar to previous studies, age ( $\leq 20$ years old) was an independent risk factor for microscopic parasitaemia after adjusting for parity [10,35-38]. Furthermore, parity had no effect on the prevalence of low grade parasitaemia in pregnant women similar to findings reported elsewhere $[16,19]$ but women $>$ 20 years had higher prevalence of low-grade parasitaemia than women $\leq 20$ years old). This suggests that age-associated immunity may play an important role in limiting $P$. falciparum to low parasite densities in areas of high and stable transmission [39]. The relationship between the role of age as a determinant of immunity and vaccine studies is not really clear. It is suggested that non-pregnancy-specific vaccines might help teenage mothers [40], but at present it is not clear whether vaccines like RTS, S is meant rather than VAR2CSA vaccines.

It is generally assumed that in areas of stable transmission, parasitaemic pregnant women are rarely symptomatic, and that severe disease or death from malaria is extremely unusual [41]. However, this assumption has been based on few studies and symptoms suggestive of malaria among pregnant women attending maternity clinics are frequent [42]. Headache, arthromyalgias and history of fever are the most common symptoms reported in pregnant women [42]. In this study, history of fever attack was common $(44 \%)$ in women during pregnancy and was associated with approximately three-fold increased risk of microscopic parasitaemia at delivery. Future studies are needed to evaluate the clinical presentation of malaria episodes during pregnancy in stable transmission areas to better control the disease. Secondly, the lack of appropriate or timely treatment of symptomatic malaria in pregnancy may lead to adverse pregnancy outcome.

Women with blood smear microscopically detectable malaria were likely to be anaemic and had a mean haemoglobin concentration of $0.98 \mathrm{~g} / \mathrm{dl}$ lower than that of uninfected women. Similar to findings reported elsewhere $[16,19,31]$ blood film microscopy identified women at highest risk of anaemia. This study did not show an association between infection detected by histology only and anaemia nor a change in mean haematocrit levels. Equally, several studies, [16,19,37] failed to obtain an association between subpatent $P$. falciparum infection in both peripheral and placental blood and increased risk of anaemia. On the contrary, in Ghana, as reported by Mockenhaupt et al [31,43], submicroscopic infections were found to be a risk factor for maternal anaemia. The impact of subpatent malaria infections on anaemia might vary with different malaria endemicity levels and therefore with the level of pre-pregnancy acquired malaria immu- 
nity [37]. Anaemia may be caused by an increase in density of parasitaemia rather than the mere presence of parasite infection.

In Malawi, Rogerson et al [16] showed that birth weights of newborns differed significantly with a diagnosis of malaria. Further, the prevalence of LBW babies was significantly higher for women with blood film microscopically detectable infection compared to those with no parasites by blood film microscopy or placental histology. The prevalence of LBW in the study area was particularly low thus it is possible that the small sample size did not provide the power needed to detect the effect of malaria on LBW. In other areas, LBW among women with malaria infection is frequently around $20 \%$ and close to $10 \%$ in those without [16]. This may explain the lack of associations. Placental monocytes and fibrin containing malaria pigment have been shown to play important roles in the pathogenesis of pregnancy-associated malaria [22]. There is the need for prospective studies in the study area that will examine the causal roles of monocyte and fibrin containing pigment in the pathogenesis of decreased birth weight and maternal anaemia.

It is not surprising that women who reported to have received one or more doses of SP had a decreased risk of microscopic parasitaemia at delivery than those who had no SP during pregnancy. Furthermore, two or more doses of SP significantly reduce the prevalence of microscopic parasitaemia among pregnant women similar to findings of previous studies $[44,45]$. The prevalence of peripheral malaria parasitaemia $(5.6 \%)$ and placental malaria parasitaemia $(25.5 \%)$ as detected by blood smear microscopy is low compared to that previously reported in the same community where peripheral and placental malaria parasitaemia (33.2\% and $33.6 \%$ respectively) were similar [13]. This study was carried out from 1998-2001 when pyrimethamine chemoprophylaxis had been recommended for use in pregnancy. It can be observed from the current study that maternal peripheral and placental malaria infection at delivery has decreased in this area confirming that IPT with SP may be effective in reducing malaria parasitaemia in pregnancy after implementation. Similar to findings reported elsewhere [35,45-47]. Approximately half of the women in the study received $\leq$ 1 SP dose. Thus a study to evaluate the coverage of IPTpSP in this area in order to identify facilitating factors and operational challenges for scaling up IPT delivery is imperative.

\section{Conclusion}

In summary, malaria in pregnancy was most sensitively diagnosed by placental histology. Younger age and history of fever attack during pregnancy were independent significant risk factors associated with microscopic parasitaemia at delivery. Blood smear microscopy identified a subset of women with malaria who had a high risk of anaemia whereas low-grade parasitaemia detected by histology only and past infection were not associated with maternal anaemia at delivery. Improving IPTp-SP coverage and adherence will substantially reduce malaria parasitaemia and maternal anaemia in pregnant women in this area. Proper diagnosis as well as ensuring appropriate and timely treatment of symptomatic malaria in pregnancy is recommended.

\section{Competing interests}

The authors declare that they have no competing interests.

\section{Authors' contributions}

JKAK: Conception and design of study, data collection, analysis, interpretation and manuscript preparation. EAA: Supervision and critically reading of manuscript for important and intellectual content. NB: Contributed in placental pathohistological studies. ESE: Design of study and critically reading of manuscript for important and intellectual content; MTB: Supervision and revision of manuscript. All authors read and approved the manuscript.

\section{Acknowledgements}

We thank the entire staff of the Mutengene Medical Centre and the mothers who volunteered to participate in this study. We are grateful to Mr Epie and all the midwives in particular for cooperation and support in this research work. Our profound gratitude to the Jean-Baptist Bengono and the entire staff of the Anatomy and Pathology Laboratory (ANAPATH), University of Yaoundé teaching hospital (CHU), Cameroon and the Department of Immunology, University of Stockholm, Sweden for their technical assistance. This investigation received financial support from MIM/ TDR/WHO Malaria research project (Grant ID: A60040; PI-Dr Achidi Eric Akum) and the Swedish Institute, Stockholm, Sweden through a guest Scholarship to J. K. Anchang-Kimbi.

\section{References}

I. Steketee RW, Nahlen BL, Parise ME, Menendez C: The burden of malaria in pregnancy in malaria-endemic areas. Am J Trop Med Hyg 200I, 64:28-35.

2. Desai M, ter Kuile FO, Nosten F, McGready R, Asamoa K, Brabin B, Newman RD: Epidemiology and burden of malaria in pregnancy. Lancet Infect Dis 2007, 7:93-104.

3. Fried M, Duffy PE: Adherence of Plasmodium falciparum to chondroitin sulfate $\mathbf{A}$ in the human placenta. Science 1996, 272:1502-I504.

4. Beeson JG, Amin N, Kanjala M, Rogerson SJ: Selective accumulation of mature Asexual Stages of Plasmodium falciparuminfected erythrocytes in the placenta. Infect Immun 2002, 70:5412-54I5.

5. Fried M, Domingo GJ, Gowda CD, Mutabingwa TK, Duffy PE: Plasmodium falciparum: Chondroitin sulfate $A$ is the major receptor for adhesion of parasitized erythrocytes in the placenta. Exp Parasitol 2006, I I 3:36-42.

6. Duffy MF, Maier AG, Byrne TJ, Marty AJ, Elliott SR, O'Neill MT, Payne $\mathrm{PD}$, Rogerson SJ, Cowman AF, Crabb BS, Brown GV: VAR2CSA is the principal ligand for chondroitin sulfate $A$ in two allogeneic isolates of Plasmodium falciparum. Mol Biochem Parasitol 2006, 148: I17-124. 
7. Menendez C, Ordi J, Ismail MR, Ventura PJ, Aponte J], Kahigwa E, Font F, Alonso PL: The impact of placental malaria on gestational age and birth weight. J Infect Dis 2000, 181:1740-5.

8. Guyatt $\mathrm{H}$, Snow RW: Malaria in pregnancy as an indirect cause of infant mortality in sub-Saharan Africa. Trans $R$ Soc Trop Med Hyg 200I, 95:569-576.

9. Uneke C): Impact of placental Plasmodium falciparum malaria on pregnancy and perinatal outcome in sub-Saharan Africa. Yale J Biol Med 2007, 80:39-50.

10. Tako EA, Zhou A, Lohoue J, Leke R, Taylor DW, Leke RF: Risk factors for placental malaria and its effect on pregnancy outcome in Yaoundé, Cameroon. Am J Trop Med Hyg 2005, 72:236-42.

II. Achidi EA, Anchang JK, Minang TJ, Boyo MA, Sinju CM, Troye-Blomberg M, Mokube JA: Malaria infection in pregnancy and its effect on haemoglobin levels in women from a malaria endemic area of Fako Division, South West Province, Cameroon. J Obstet Gynaecol 2005, 25:235-240.

12. Achidi EA, Anchang JK, Minang TJ, Ngum B, Boyo MA, Troye-Blomberg M, Mokube JA: The effect of maternal, umbilical cord and placental malaria parasitaemia on birth weight of newborn. Acta Paediatr. 2005, 94(7):917-923.

13. Achidi EA, Anchang JK, Minang TJ, Mokube JA, Troye-Blomberg M: Studies on Plasmodium falciparum isotypic antibodies and numbers of IL-4 and IFN- $\gamma$ secreting cells in paired maternal cord blood from South West Cameroon. Int J Infect Dis 2005, 9:159-169.

14. Ismail MR, Ordi J, Menendez C, Ventura PJ, Aponte J], Kahigwa E, Hirt $\mathrm{R}$, Cardesa A, Alonso PL: Placental pathology in malaria: a histological, immunohistochemical, and quantitative study. Human Pathol 2000, 3 I:85-93.

15. Okoko BJ, Ota MO, Yamuah LK, Idiong D, Mkpanam SN, Avieka A, Banya WAS, Osinusi K: Influence of placental malaria infection on foetal outcome in the Gambia: twenty years after lan McGregor. J Health Popul Nutr 2002, 20:4-II.

16. Rogerson SJ, Mkundika P, Kanjala MK: Diagnosis of Plasmodium falciparum malaria at delivery: comparison of blood film preparation methods and of blood films with histology. J Clin Microbiol 2003, 41: 1370-1374.

17. Leke RFG, Djokam RR, Mbu R, Leke RJ, Fogako J, egnekou R, Metenou S, Sama G, Zhou Y, Cadigan T, Parra M, Taylor DW: Detection of the Plasmodium falciparum antigen histidine-rich protein 2 in blood of pregnant women: implications for diagnosing placental malaria. J Clin Microbiol 1999, 37:2992-2996.

18. Mockenhaupt FP, Bedu-Addo G, von Gaertner C, Boyé R, Fricke K, Hanniball I, Karakaya F, Schaller M, Ulmen U, Acquah PA, Dietz E, Eggelte TA, Bienzle U: Detection and clinical manifestation of placental malaria in southern Ghana. Malar / 2006, 5: I I 9

19. Walker-Abbey A, Djokam RRT, Eno A, Leke RFG, Titanji VPK, Fogako J, Sama G, Thuita LH, Beardslee E, Snounou G, Zhou A, Taylor $D W:$ Malaria in pregnant Cameroonian women: The effect of age and gravidity on submicroscopic and mixed-species infections and multiple parasite genotypes. Am J Trop Med Hyg 2005, 72:229-235.

20. Kassam SN, Nesbitt S, Hunt LP, Oster N, Soothill P, Sergi C: Pregnancy outcomes in women with or without placental malaria infection. Int J Gynaecol Obstet 2006, 93:225-232.

21. Shulman C, Dorman EK: Reducing childhood mortality in poor countries: Importance and prevention of malaria in pregnancy. Trans R Soc Trop Med Hyg 2003, 97:30-35.

22. Rogerson SJ, Pollina E, Getachew A, Tadesse E, Lema VM, Molyneux ME: Placental monocyte infiltrates in response to Plasmodium falciparum infection and their association with adverse pregnancy outcomes. Am J Trop Med Hyg 2003, 68:1 I5-19.

23. Wanji S, Tanke T, Atanga SN, Ajonina C, Nicholas T, Fontenille D: Anopheles species of the mount Cameroon region: biting habits, feeding behaviour and entomological inoculation rates. Trop Med Int Health 2003, 8:643-9.

24. Wanji S, Kimbi HK, Eyong JE, Tendongfor N, Ndamukong JL: Performance and usefulness of the Hexagon rapid diagnostic test in children with asymptomatic malaria living in the Mount Cameroon region. Malar / 2008, 7:89.

25. Hill J, Kazembe P: Reaching the Abuja target for intermittent preventive treatment of malaria in pregnancy in African women: a review of progress and operational challenges. Trop Med Int Health 2006, I I:409-4I8.
26. Rooth I, Perlmann H, Bjorkman A: Plasmodium falciparum reinfection in children from holoendemic area in relation to seroreactivities against oligopeptides from different malaria antigens. Am J Trop Med Hyg I99I, 45:309- 18.

27. Romagosa C, Menendez C, Ismail MR, Quintó L, Ferrer B, Alonso PL, Ordi J: Polarisation microscopy increases the sensitivity of hemozoin and Plasmodium detection in the histological assessment of placental malaria. Acta Trop 2004, 90:277-284.

28. Topley E: Anaemia in rural Africa: community support for control activities where malaria is common. Available through FSG. Medimedia Vine house. Fair Green Reach. Cambridge CB5 OJD. UK 1998:2.

29. WHO: Iron deficiency anaemia: assessment, prevention and control. Geneva: World Health Organization; 2001.

30. Shulman CE, Marshall T, Dorman EK, Bulmer JN, Cutts F, Peshu N, Marsh K: Malaria in pregnancy: adverse effects on haemoglobin levels and birthweight in primigravidae and multigravidae. Trop Med Int Health 200I, 6:770-778.

31. Mockenhaupt FP, Ulmen U, von Gaertner C, Bedu-Addo G, Bienzle U: Diagnosis of placental malaria. J Clin Microbiol 2002, 40:306-308.

32. Snounou G, Viriyakosol S, Zhu XP, Jarra W, Pinheiro L, Rosano V, Thaithong S, Brown N: High sensitivity of detection of human malaria parasites by the use of nested polymerase chain reaction. Mol Biochem Parasitol 1993, 6 I:3 15-320.

33. Uneke C], lyare FE, Oke P, Duhlinska DD: Assessment of malaria in pregnancy using rapid diagnostic tests and its association with HIV infection and haematologic parameters in SouthEastern Nigeria. Haematologica 2008, 93: | 43-144.

34. Brabin BJ: The risks and severity of malaria in pregnant women. Applied Field Research Report No. I, UNDP/World Bank/WHO Special Programme for Research and Training in Tropical Diseases, Geneva 1991:1-52.

35. Rogerson SJ, Broek NR Van den, Chaluluka E, Qongwane C, Mhango CG, Molyneux ME: Malaria and anemia in antenatal women in Blantyre, Malawi: a twelve-month survey. Am J Trop Med Hyg 2000, 62:335-340

36. Bouyou-Akotet MK, lonete-Collard DE, Mabika-Manfoumbi M, Kendjo E, Matsiegui PB, Mavoungou E, Kombila M: Prevalence of Plasmodium falciparum infection in pregnant women in Gabon. Malar J 2003, 2:18.

37. Saute F, Menendez C, Mayor A, Aponte J, Gomez-Olive X, Dgedge M, Alonso $P$ : Malaria in pregnancy in rural Mozambique: the role of parity, submicroscopic and multiple Plasmodium falciparum infections. Trop Med lnt Health 2002, 7:19-28.

38. Dicko A, Mantel C, Thera MA, Doumbia S, Diallo M, Diakite M, Sagara I, Doumbo OK: Risk factors for malaria infection and anaemia for pregnant women in the Sahel area of Bandiagara, Mali. Acta Trop 2003, 89:17-23.

39. Oeuvray C, Theisen M, Rogier C, Trape JF, Jepsen S, Druilhe P Cytophilic immunoglobulin responses to Plasmodium falciparum glutamate-rich protein are correlated with protection against clinical malaria in Dielmo, Senegal. Infect Immun 2000, 68:2617-2620.

40. Rogerson SJ, Mwapasa V, Meshnick SR: Malaria in pregnancy: linking immunity and pathogenesis to prevention. Am J Trop Med Hyg. 2007, 77(6 Suppl ): I 4-22.

4I. Nosten F, Rogerson SJ, Beeson JG, McGready R, Mutabingwa TK, Brabin $B$ : Malaria in pregnancy and the endemicity spectrum: what can we learn? Trends Parasitol 2004, 20:425-432.

42. Bardají A, Sigauque B, Brunil L, Romagosa C, Sanz S, Mabunda S, Mandomando I, Aponte J, Sevene E, Alonso PL, Menéndez C: Clinical malaria in African pregnant women. Malar J 2008, 7:27.

43. Mockenhaupt FP, Rong B, Till H, Eggelte TA, Beck S, Gyasi-Sarpong C, Thompson WNA, Bienzle U: Submicroscopic Plasmodium falciparum infections in pregnancy in Ghana. Trop Med Int Health. 2004, 5(3): 167- 173.

44. Shulman CE, Dorman EK, Cutts F, Kawuondo K, Bulmer JN, Peshu N, Marsh K: Intermittent sulphadoxine-pyrimethamine to prevent severe anaemia secondary to malaria in pregnancy: a randomised placebo-controlled trial. Lancet 1999, 353:632-36.

45. Challis K, Osman NB, Cotiro M, Nordahl G, Dgedge M, Bergstrom S: Impact of a double dose of sulphadoxinepyrimethamine to reduce prevalence of pregnancy malaria in southern Mozambique. Trop Med Int Health 2004, 9: 1066-73. 
46. Sirima SB, Cotte AH, Konate A, Moran AC, Asamoa $\mathrm{K}$, Bougouma EC, Diarra A, Ouedraogo A, Parise ME, Newman RD: Malaria prevention during pregnancy: assessing the disease burden one year after implementing a program of intermittent preventive treatment in Koupela District, Burkina Faso. Am J Trop Med Hyg 2006, 75:205-2II.

47. Hommerich L, von Oertzen C, Bedu-Addo G, Holmberg V, Acquah PA, Eggelte TA, Bienzle U, Mockenhaupt FP: Decline of placental malaria in southern Ghana after the implementation of intermittent preventive treatment in pregnancy. Malar J 2007, 6:144.

Publish with Bio Med Central and every scientist can read your work free of charge

"BioMed Central will be the most significant development for disseminating the results of biomedical research in our lifetime. "

Sir Paul Nurse, Cancer Research UK

Your research papers will be:

- available free of charge to the entire biomedical community

- peer reviewed and published immediately upon acceptance

- cited in PubMed and archived on PubMed Central

- yours - you keep the copyright

Submit your manuscript here:

http://www.biomedcentral.com/info/publishing_adv.asp 